\title{
New validated UPLC method for the determination of tiemoniummethylsulphate in pharmaceutical and biosamples
}

\begin{abstract}
A new method has been described to determine Tiemonium methylsulphate in biofluids and pharmaceutical samples by UPLC with a UV detector set at $240 \mathrm{~nm}$. Reversedphase Gemini $3 \mathrm{U}, \mathrm{C} 18,110 \mathrm{R}(150 \times 4.6 \mathrm{~mm}, 3 \mu \mathrm{m})$ column has been used with a mobile phase composition consisting $\mathrm{CH}_{3} \mathrm{OH}, \mathrm{CH}_{3} \mathrm{CN}$ and $\mathrm{NaH}_{2} \mathrm{PO}_{4}$ under isocratic program. When it is eluted at a short of $1.12 \mathrm{~min}$. A careful liquid-phase extraction was optimized to isolate the drugs from biofluids. The results were linear upto $10 \mu \mathrm{g} \mathrm{mL}^{-1}$ with the correlation coefficients greater than 0.998 . The sensitivity limits, LOD and LOQ were 0.12 and $0.37 \mu \mathrm{g} \mathrm{mL}^{-1}$, respectively. The method is simple, fast and reliable with good specificity and sensitivity and will be suitable for routein analysis of the drug.
\end{abstract}

Keywords: diseases, gastroenteritis, diarrhea, dysentery, biliary colic, enterocolitis, cholecystytis, colonopathyes, mild cystitis, spasmodic dysmenorrhoea, tiemonium methylsulphate, $\mathrm{CH}_{3} \mathrm{OH}, \mathrm{CH}_{3} \mathrm{CN}, \mathrm{NaH}_{2} \mathrm{PO}_{4}$
Volume 5 Issue 2 - 2017

\author{
Mohammad Nasir Uddin,' Monir Uddin, \\ Touhid Kabir,' Suman Das ${ }^{2}$ \\ 'Department of Chemistry, University of Chittagong, Bangladesh \\ ${ }^{2}$ BCSIR Laboratories, Chittagong, Bangladesh
}

Correspondence: Mohammad Nasir Uddin, Department of Chemistry, University of Chittagong, Bangladesh, Email nasircu72@gmail.com

Received: November 0I, 2016 | Published: April 10, 2017

\section{Introduction}

Tiemonium methylsulphate (TMS) 4-[3-Hydroxy-3-phenyl-3-(2thienyl) propyl]-4-methyl morpholinium methyl sulphate (Figure 1) is a quaternary ammonium antimuscarinics. Having the peripheral effects as that of atropine it is used in the release of visceral spasms. Muscle seizures of the intestine, biliary system, uterus and urinary bladder is reduced by it. In case of the pain in gastrointestinal and biliary disease in the urology and gynecology it is prescribed. Diseases include gastroenteritis, diarrhea, dysentery, biliary colic, enterocolitis, cholecystytis, colonopathyes, mild cystitis, and spasmodic dysmenorrhoea. ${ }^{1}$ The patient need to be urgent hospitalized to avoid the risk of mortality in case of immediately discontinue tiemonium which perform emergency blood count in the event of appearance of fever, sore throat or mouth ulcers. In view of the above considerations, versatile analytical procedure is needed to assay this drug in a setting where a patient used it. Detecting sensitivity cannot be predicted or still not available prior to treatment and during treatment even agranulocytosis development. In recentyears a few spectrophotometric methods are reported. ${ }^{2}$ Tiemonium Methyl Sulfate has been spectrophotometrically determined via ion pair complex formation and oxidation reaction based on oxidation of the studied drugs with ammonium vanadate in sulfuric acid. ${ }^{3}$ Few validated spectrophotometric methods are available for tiemonium methylsulphate (TMS) determination and to study its stability in pharmaceutical dosage form (Figure 1). ${ }^{4,5}$

Chromatographic methods, thin layer chromatography, high performance thin layer chromatographic, high-performance liquid chromatography, and micellar-electrokinetic chromatography with different detection systems are generally preferred for their greater selectivity and simplicity. All these have resulted in simple and sensitive methods for separation and determination of this drug alone and in combination with other drugs. A few high-performance liquid chromatographic methods were developed and validated for the determination of tiemonium methylsulphate. ${ }^{6,7}$ Therefore, present study attempts to develop a UPLC method coupled with DAD detection and to study degradation kinetics of tiemonium methylsulphate. Method is successfully applied to pharmaceutical and biological samples.<smiles>COS(=O)(=O)[O-]</smiles>

Figure I Structure of tiemoniummethylsulphate.

\section{Materials and methods}

\section{Materials}

HPLC-grade methanol was supplied by Sigma-Aldrich (Germany), ACN was supplied by Scharlau (Scharlab S.L, Spain) and sodium dihydrogen phosphate was supplied by Applichem $\mathrm{GmbH}$ (Germany). Water used throughout the study was purified by the reverse osmosis method to gain high-purity water with a Milli-Q water purification system from Millipore (Millipore, Bedford, MA, USA). Purity of reference compounds was not less than $98 \%$. Pharmaceutical formulations commercially available in Bangladesh were analysed to check the applicability of the method: Torax $(10 \mathrm{mg})$ tablet by Square, Rolac(10mg) tablet by Renata, Etorac(10mg) tablet by Incepta, Zidolac $(10 \mathrm{mg})$ tablet by Beximco, ketonic $(10 \mathrm{mg})$ tablet by $\mathrm{SK}+\mathrm{F}$, Torax $(30 \mathrm{mg})$ injection by Square, Rolac(30mg) injection by Renata, Norvis $(50 \mathrm{mg})$ tablet by Square, Visceralgin $(50 \mathrm{mg})$ tablet by Nuvista, Timozin $(50 \mathrm{mg})$ tablet by Incepta , Visrul $(50 \mathrm{mg})$ 
tablet by Opsonin, Algin $(50 \mathrm{mg})$ tablet by Renata, Visceralgin $(5 \mathrm{mg})$ Injection by Nuvista, align $(5 \mathrm{mg})$ Injection by Renata, align $(10 \mathrm{mg})$ syrup by renata, visrul(10mg) syrup by opsonin. Biological samples, blood or urine $(4 \mathrm{~mL})$ were collected in bottles from the male patient under treatment with Algin after 1hour of injection administration in Chittagong medical college and hospital, Bangladesh.

\section{Preparation of standards}

Stock solutions of Tiemoniummethyl sulphate were prepared at concentration level $100 \mu \mathrm{gL}^{-1}$ by dissolving an appropriate amount of each compound in ethanol and were stored at $4^{\circ} \mathrm{C}$, protected from light and used within 3 months. The stock solutions of drugs were further serially diluted daily before analysis with ethanol to make interim mixture solutions (controlled solution) at concentrations of 1 , $3,5,7,10 \mu \mathrm{g} \mathrm{mL} \mathrm{m}^{-1}$ for the compound. Buffer: $5 \mathrm{mM}$ aqueous solution of dihydrogen sodium phosphate buffer was prepared by mixing appropriate weight in Milli Q water and filtered before use.

\section{Sample preparation}

Pharmaceutical Samples Twenty tablets were finely ground and powdered. A portion equivalent to $100 \mu \mathrm{g} \mathrm{mL} \mathrm{mL}^{-1}$ solution was accurately weighed and transferred to volumetric flask and dissolved. Total volume made up to the mark diluting with ethanol. The solution was sonicated for $15 \mathrm{~min}$ and centrifuged at $3000 \mathrm{rpm}$ for $10 \mathrm{~min}$, and filtered through a $0.22 \mu \mathrm{m}$ PTFE syringe filter with Whatman filter paper. An aliquot portion was transferred to volumetric flask, diluted with ethanol as to provide a stock solution of $100 \mu \mathrm{g} \mathrm{mL}^{-1}$. All stock solutions were stored at $4^{\circ} \mathrm{C}$ in refrigerator. Dilution has been made to accurately measured aliquots of the stock solution with ethanol to give working concentrations of the analyte.

\section{Blood samples}

$0.5 \mathrm{~mL}$ upper layer of the blood after centrifugation were taken in each of three vials. $0.5 \mathrm{~mL}$ acetonitrile were added into each vial. For blank solution $1 \mathrm{~mL}$ ethanol were added into a vial and remaining two vials were spiked with the addition of $1 \mathrm{~mL}$ of 1 and $3 \mu \mathrm{g} \mathrm{mL}^{-1}$ standard solution. The solution was sonicated for $15 \mathrm{~min}$ and centrifuged at $3000 \mathrm{rpm}$ for $10 \mathrm{~min}$, and filtered through a $0.22 \mu \mathrm{m}$ PTFE syringe filter with Whatman filter paper. All solutions were stored at $4{ }^{\circ} \mathrm{C}$ in refrigerator before analysis.

\section{Urine samples}

$1 \mathrm{~mL}$ of Urine was taken in each of three vials. For blank solution $1 \mathrm{~mL}$ ethanol were added into a vial and remaining two vials were spiked with the addition of $1 \mathrm{~mL}$ of 1 and $3 \mu \mathrm{g} \mathrm{mL}^{-1}$ standard solution. The solution was sonicated for $15 \mathrm{~min}$ and centrifuged at 3000 rpm for $10 \mathrm{~min}$, and filtered through a $0.22 \mu \mathrm{m}$ PTFE syringe filter with Whatman filter paper. All solutions were stored at $4^{\circ} \mathrm{C}$ in refrigerator before analysis.

\section{Preparation of calibration curve}

Calibration curves were construced for five concentration levels of the analyte ranging from $1,3,5,7$ and $10 \mu g \mu \mathrm{L}^{-1}$. Peak area of each chromatogram at different levels was plotted against theoretical concentrations. Calibration curve so construced was fitted by a least squares linear regression to the equation, $\mathrm{y}=\mathrm{mx}+\mathrm{c}$. where, $\mathrm{y}=$ response ratio, $\mathrm{m}=$ slope, $\mathrm{x}=$ concentration, $\mathrm{c}=$ intercept. With reference to this calibration equation unknown concentration of the analyte was determined.

\section{Chromatographic conditions}

A standard solution of $5 \mu \mathrm{g} \mathrm{mL} L^{-1}$ drug was used for the optimization of the chromatographic conditions. All through the experiment a reversed-phase Gemini 3U, C18, 110R $(150 \times 4.6 \mathrm{~mm}, 3 \mu \mathrm{m})$ column and $\mathrm{NaH}_{2} \mathrm{PO}_{4}$ (dihydrogen sodium phosphate, $5 \mathrm{mM}$ ) were used as buffer solution. Special attention has been paid on optimization of the mobile phase composition. To detect the absorption maxima a UV scan of standard solution prepared by mobile phase was done in the range of 200 to $400 \mathrm{~nm}$ for the spectra of studied drugs. An efficient UPLC method was evaluated by the satisfactory results with good resolution at reduced elution time and tailing problems under this optimized composition. With respect to sharpness and symmetry of the peaks best flow rate was investigated. Different composition of mobile phase consisting $\mathrm{CH}_{3} \mathrm{OH}, \mathrm{CH}_{3} \mathrm{CN}$ and $\mathrm{NaH}_{2} \mathrm{PO}_{4}$ under isocratic program was checked as the optimized conditions at a flow rate of $1 \mathrm{~mL} / \mathrm{min}$ at ambient temperature. The injection volume was $10 \mu \mathrm{L}$. Prior to the analysis buffer solution was filtered in vacuum using $0.2 \mu \mathrm{m}$ membrane, mobile phase was degassed by a stream of helium and column was equilibrated with the mobile phase.

\section{Validation parameters}

$\mathrm{ICH}^{8}$ guide lines were followed for the validation of the method. In this regard analytical performance parameters precision, accuracy, specificity, limit of detection, limit of quantitation, linearity and range, suitability and robustness were studied.

\section{Linearity}

For the study of linearity calibration curve was constructed for TMS at five concentration levels of standard solution when triplicate measurements were taken for each concentration. Calibration curve was constructed using peak area versus nominal concentrations of the analytes. The slope, intercept, and correlation coefficient was obtained from the least square linear regression analysis of the data.

\section{Accuracy}

Aliquots of $10 \mu \mathrm{L}$ of the standard solutions at five concentration levels were injected into the UPLC system when triplicate measurements were recorded for each concentration. The nominal values of the TMS contents in each solution were calculated using the regression equations. Percent recoveries of the particular components in the solution were expressed as [mean found concentration/ theoretical concentration] $\times 100$.

\section{Precision}

The precision was determined by calculating the standard deviation (SD) and the relative standard deviation (RSD) for the replecate measurements between nominal and calculated concentrations of each level. Intraday repeatability was determined in six replicates at five assay levels of TMS standard within day. The procedure was repeated to determine inter-day repeatability on six consecutivedays at same levels in standard solutions.

\section{Selectivity}

The selectivity is the ability to measure the analyte of interest accurately in the presence of other components that might be expected in the sample matrices. It demonstrates that analytes were free of interference from degradation products or excipients in pharmaceutical or biological samples. It might be confirmed by ensuring that peak 
response in the same retention times is due to examined components only.

\section{Sensitivity}

Limit of detection (LOD and the limit of quantitation (LOQ) were calculated by data analysis by ANOVA program with acceptable precision and accuracy to test the sensitivity of the method. These were calculated from calibration graph by the formula, $\mathrm{LOD}=3 \cdot \mathrm{S}_{\mathrm{xy}} / \mathrm{a}$ and $\mathrm{LOQ}=10 \cdot \mathrm{S}_{\mathrm{xy}} / \mathrm{a}$. Where, $\mathrm{S}_{\mathrm{xy}}=$ standard deviation of the response and $\mathrm{a}=$ slope of the calibration curve.

\section{Stability}

For long-term stability assay standard solutions were examined by the proposed method over a period of 30days. The freshly prepared solutions were stored for the 30days in a refrigerator at both $4^{\circ} \mathrm{C}$. Each sample was analyzed after sevendays intervel for intact compounds once daily for investigation of stability. Recovery and RSD of the stored samples were compared to that of freshly prepared samples.

\section{Robustness}

The capacity to remain TMS unaffected during the investigation by small variations in method parameters e.g. flow rate or wavelength of scanning is the robustness of the method. It has been evaluated by determining the effect (if any) on the results of the method.

\section{Column efficiency}

For a representative chromatogram the column efficiency parameters have been calculated by the relations, $k=\mathrm{t}_{\mathrm{R}}-\mathrm{t}_{0} / \mathrm{t}_{0}, N=16$ $\left(\mathrm{t}_{\mathrm{R}} / \mathrm{w}\right)^{2}$ and $T_{f}=(\mathrm{a}+\mathrm{b}) / 2 \mathrm{a}$ for retention factor, theoretical plate number and tailing or asymmetry factor, respectively. Where, $t_{0} t_{R}$ are the retention times and $\mathrm{w}_{1}, \mathrm{w}_{2}$ are the baseline peak width of adjacent peaks.

\section{Results and discussion}

\section{Chromatography}

The detection wavelength at $235 \mathrm{~nm}$ was selected for monitoring as compromised to the drug (Figure 2) from the absorption spectrum of tiemoniummethylsulphate. Solvent composition and mobile phase flow rate were optimized as the chromatographic conditions which must elute the TMS with satisfactory peak shape and in a short time. Initial experiments were performed using methanol or acetonitrile as organic modifier in the buffered mobile phase for better elution of TMS. The combination of methanol with dihydrogen sodium phosphate $(5 \mathrm{mM}$ $\mathrm{NaH}_{2} \mathrm{PO}_{4}$ ) buffer served our intentions best. Addition of acetonitrile increases the intensity of peak. All through the experiment reversedphase Gemini 3U, C18, 110R $(150 \times 4.6 \mathrm{~mm}, 3 \mu \mathrm{m})$ column was used for the determination of tiemonium methylsulphate. The mobile phase mixture of $\mathrm{CH}_{3} \mathrm{OH}, \mathrm{CH}_{3} \mathrm{CN}$ and $5 \mathrm{mM} \mathrm{NaH}_{2} \mathrm{PO}_{4}$ by the composition of 90:5:5 $(v / v)$ was optimized at isocratic program (Table 1). Peak tailing observed was considerable with this mobile phase composition. Under this composition the effect on $\mathrm{R}_{\mathrm{p}}$ peak height and peak width was studied to determine the flow-rate the mobile phase. It was expected that with the increase of the mobile-phase flow-rate $R_{t}$ was decreased. A flow-rate of $1 \mathrm{~mL} \mathrm{~min}^{-1}$ was chosen as a compromise analysis time. This rate also maintains good peak shape. This optimized conditions were followed to carry out the detection and quantitation of TMS TMS was eluted by the total of $1.22 \mathrm{~min}$ ( $1.22 \pm 0.04$ minutes). Figure 3 is the typical UPLC chromatogram of the examined drug $\left(10 \mu \mathrm{gL}^{-1}\right)$ in described chromatographic conditions.

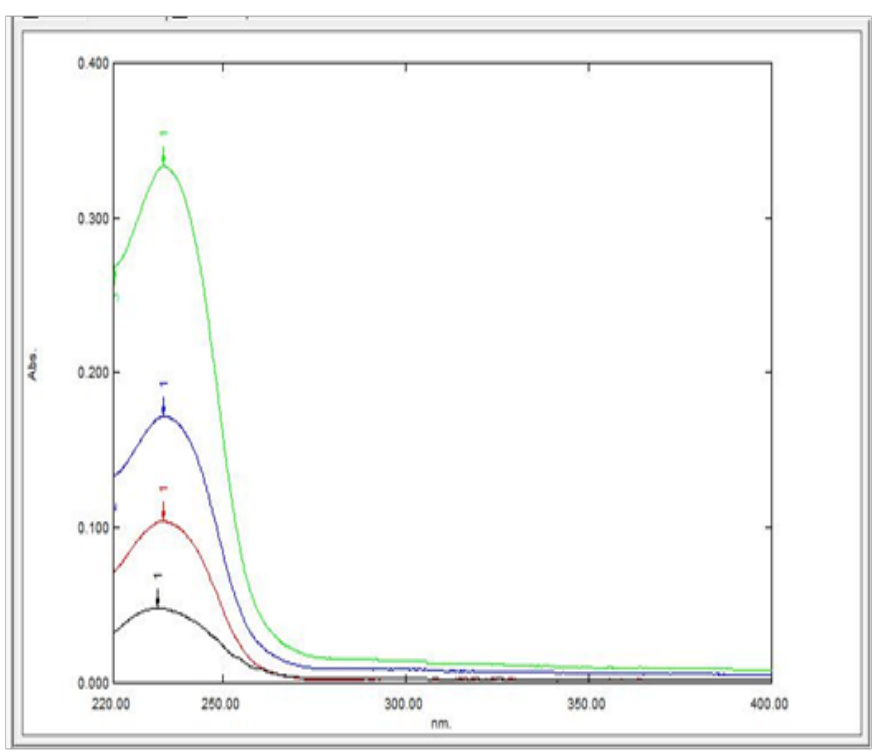

Figure 2 UV scan of standard solution for the spectra of studied drugs in the range of $200-400 \mathrm{~nm}$.

This optimized method was applied to various pharmaceutical products and biofluids, plasma and urine samples for determining the content of TMS. Intraday and inter-day precision and accuracy data as summarized in (Table 2) indicates that these values satisfy the analytical agreement best. The validation performance of the proposed UPLC method has been shown in Table 3. System suitability and robustness and the column efficiency data as the validation evidences are placed in Table $4 \& 5$ respectively. The results of pharmaceutical samples and plasma and urine analysis have been presented in Table $6 \& 7$, respectively.

Table I Optimum gradient program for the proposed method

\begin{tabular}{|c|c|c|c|c|c|}
\hline \multirow{2}{*}{$\begin{array}{l}\text { Time } \\
\text { min }\end{array}$} & \multicolumn{3}{|c|}{ Solvent composition } & \multirow{2}{*}{$\begin{array}{l}\text { Flow } \\
\text { rateMI/ } \\
\text { Min }\end{array}$} & \multirow{2}{*}{$\begin{array}{l}\text { R. } \\
\text { time(Min) }\end{array}$} \\
\hline & $\mathrm{CH}_{3} \mathrm{CN}$ & $\mathrm{CH}_{3} \mathrm{OH}$ & $\begin{array}{l}5 \mathrm{mM} \\
\mathrm{NaH}_{2} \mathrm{PO}_{4}\end{array}$ & & \\
\hline $0.01-3.0$ & 5 & 90 & 5 & 1 & $1.22 \pm 0.04$ \\
\hline
\end{tabular}

Table 2 Summarizes Intraday and inter-day precision and accuracy data

\begin{tabular}{|c|c|c|c|c|}
\hline \multirow{2}{*}{ Analysis } & \multicolumn{2}{|c|}{ Conc. $\mu \mathrm{g}$ mL-I } & \multirow{2}{*}{$\begin{array}{l}\text { RSD } \\
\text { (\%) }\end{array}$} & \multirow{2}{*}{ Recovery (\%) } \\
\hline & Added & Found & & \\
\hline \multirow{5}{*}{ Intraday } & I & $0.97 \pm 0.004$ & 2.8 & 97.13 \\
\hline & 3 & $2.98 \pm 0.014$ & 2.9 & 99.29 \\
\hline & 5 & $5.03 \pm 0.043$ & 5 & 100.63 \\
\hline & 7 & $7.08 \pm 0.057$ & 4.7 & 101.17 \\
\hline & 10 & $9.94 \pm 0.591$ & 3.5 & 99.35 \\
\hline \multirow{5}{*}{ inter-day } & 1 & $0.99 \pm 0.05$ & 2.8 & 98.81 \\
\hline & 3 & $2.99 \pm 0.02$ & 5.2 & 99.54 \\
\hline & 5 & $5.02 \pm 0.04$ & 5.5 & 100.32 \\
\hline & 7 & $7.07 \pm 0.04$ & 3.4 & 101.05 \\
\hline & 10 & $9.91 \pm 0.06$ & 3.6 & 99.14 \\
\hline
\end{tabular}


Table 3 Validation performance of the proposed UPLC method

\begin{tabular}{|c|c|}
\hline Validation parameters & (TMS) \\
\hline Measurement wavelength (nm) & 235 \\
\hline Linear range $\left(\mu g \mathrm{~mL}^{-1}\right)$ & $0.01-10$ \\
\hline Linearity equation & $y=16780 x+874.43$ \\
\hline Standard deviation of the slope & 0.005 \\
\hline Correlation coefficient (r) & 0.997 \\
\hline \multicolumn{2}{|l|}{ Relative standard deviation (\%RSD) } \\
\hline Intraday & $2.9-5.0$ \\
\hline Inter day & $2.8-5.5$ \\
\hline \multicolumn{2}{|l|}{ Relative standard deviation (\%R) } \\
\hline Intraday & $99.13-101.17$ \\
\hline Inter day & $98.81-101.05$ \\
\hline Limit of detection, LOD $\left(\mu \mathrm{g} \mathrm{mL} \mathrm{L}^{-1}\right)$ & 0.12 \\
\hline Limit of quantification, LOQ $\left(\mu \mathrm{g} \mathrm{mL}^{-1}\right)$ & 0.37 \\
\hline
\end{tabular}

Table 4 Validation parameters in terms of suitability and robustness

\begin{tabular}{|c|c|c|c|}
\hline \multirow{3}{*}{$\begin{array}{l}\text { Conc. (5 } \mu g \\
\left.\mathrm{~mL}^{-1}\right)\end{array}$} & \multicolumn{2}{|c|}{ Suitability } & \multirow{2}{*}{$\begin{array}{l}\text { Robustness } \\
\text { (Recovery,\%) }\end{array}$} \\
\hline & R.T & Area & \\
\hline & $(n=5)$ & $(n=5)$ & $(0.9 \mathrm{~mL} / \mathrm{min})$ \\
\hline Average & $1.22 \pm 0.04$ & $85293.5 \pm 62.17$ & 99.48 \\
\hline RSD (\%) & 0.34 & 0.07 & 0.04 \\
\hline
\end{tabular}

Table $\mathbf{5}$ Validation parameters in term of column efficiency

\begin{tabular}{lllll}
\hline $\begin{array}{l}\text { V. } \\
\text { Parameters }\end{array}$ & NTP & HETP & T.F & C.F, $\mathbf{k}^{\prime}$ \\
\hline Average & $740.75 \pm 7.92$ & $16 \mathrm{I} . \mathrm{II} \pm 8.7$ & $1.97 \pm 0.073$ & $0.675 \pm 0.002$ \\
RSD & 1.06 & 5.45 & 3.73 & 0.32 \\
\hline
\end{tabular}

\section{Method validation}

The optimized UPLC method using a simple mobile phase provides a rapid quality control determination of TMS in standard, pharmaceutical and biological samples. The parameters linearity, selectivity, extraction recovery, precision, accuracy, stability and robustness were dicussed for validation of the method.

\section{Linearity}

For five standard working concentration ranging 1.0, 3.0, 5.0, $7.0,10.0 \mu \mathrm{g} \mathrm{mL}^{-1}$ of tiemoniummethylsulphates a calibration curve was constructed plotting peak area (y) of drug versus nominal concentrations $(\mathrm{x})$. Calibration equation, $\mathrm{y}=16780 \mathrm{x}+874.43$ with a coefficients of determination $\left(r^{2}\right) 0.9997$ was obtained which was used to estimate unknown concentration. The calibration curve was linear in the range of $0.5-10 \mu \mathrm{g} \mathrm{mL}^{-1}$ for TMS. The calibration curve constructed for the determination of TMS is shown in Figure 3.

\section{Sensitivity}

The limit of detection and the limit of quantification were calculated from calibration graph by the formula, $\mathrm{LOD}=3 \cdot \mathrm{S} / \mathrm{xy}$ and $\mathrm{LOQ}=10 \cdot \mathrm{S}_{\mathrm{xy}} / \mathrm{a}$, respectively. The values of LOD and LOQ were found to be 0.12 and $0.37 \mu \mathrm{g} \mathrm{mL}^{-1}$, respectively. These values indicate that method is sensitive enough for therapeutic assay.

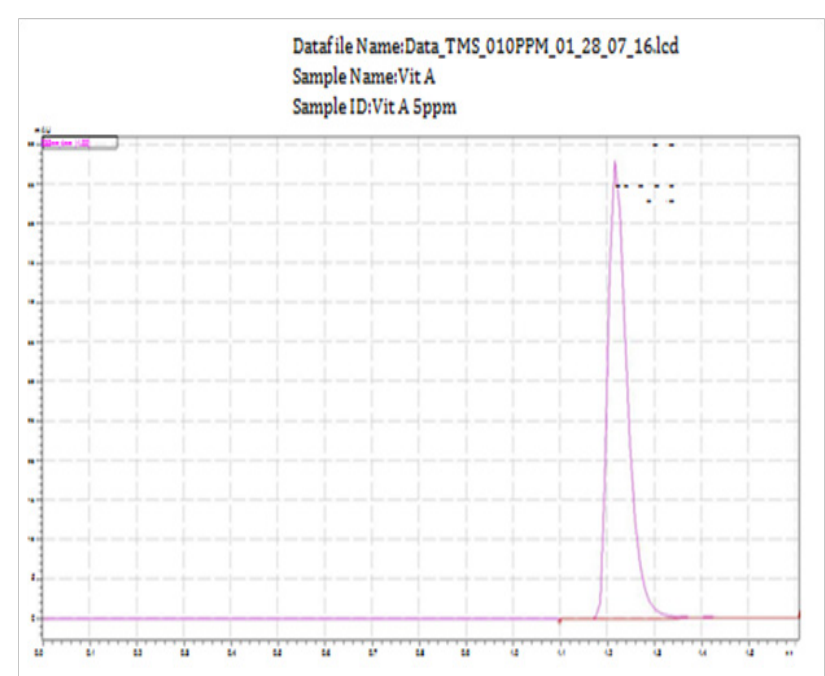

Figure 3 Typical UPLC chromatogram of the examined drug $\left(10 \mu g \mathrm{~mL}^{-1}\right)$ in Chromatographic

conditions described in text. Peaks, 1.21 min (TMS).

\section{Accuracy}

Recovery was calculated for five concentrations of standard solution analyzed within day for intraday assay and at six differentdays for inter-day assay while triplicate measurements were taken for each concentration level. The results of recovery studies of the proposed method were $99.13-101.17 \%$ for intraday and 98.81 $101.05 \%$ for inter-day assay. It was indicated high accuracy of the drug determination. Intraday and inter-day recovery data of proposed method are presented in Table 2.

Determination of TMS free of interference from potential impurities and degradation products which is indicated by the absence of any peak in the same retention times demonstrates the method selectivity. It was checked by injecting TMS standard solution, background control sample. Peak purity of TMS peak was passed in standard. From the chromatogram in Figure 4 it is shown that there was no other peak on the retention times $\left(\mathrm{R}_{t}=1.20 \mathrm{~min}\right)$ of TMS. It is evident that under the chosen chromatographic conditions TMS did not suffer interference from the formulation excipients or impurities from biosamples. Results indicate the high specificity or selectivity of the proposed UPLC method and it can be used in a stability assay and routine analysis of the TMS.

\section{Robustness}

In small deliberate changes of experimental parameters including the flow rate and scanning wavelength recoveries (\%R) were excellent under most conditions and remained unaffected (Table 1). Retention time was extended due to the decreas of flow rate as expected. No remarkable difference between two chromatograms was observed when the wavelength was varied by $\pm 3 \mathrm{~nm}$. Observation in variation in these experimental parameters provided an indication of method's reliability that concluded the method's robustasness as well.

\section{System suitability}

An integral part of the method development is system suitability 
test. It is used to verify whether the system is adequate for the analysis of drug. By the replicate injections $(n=5)$ of the sample at $5 \mu \mathrm{gmL}^{-1}$ concentration level the system suitability of TMS estimation was assessed. To evaluate the system suitability both Intraday and inter-day assessments for standard were performed and precision of retention time and peak area was examined. As shown in (Table 4) RSD of the peak area was $0.07 \%$ and that of retention time was $0.34 \%$. it indicates the excellent suitability of the system.

\section{Stability}

The stability of TMS in methanol stored in the fridge $\left(4^{\circ} \mathrm{C}\right)$ was analyzed at five intervals during the period of 30days. The results were compared with those from freshly prepared standard solution. The results showed that the retention time and peak area of TMS remained almost unchanged having the standard devition \pm 0.04 and \pm 62.17 , respectively. No significant degradation within the period was identified though peak intensity was decreased gradually. Up to 15 days stored at $4{ }^{\circ} \mathrm{C}$ recovery of the compound was greater than $85 \%$ as shown in Figure 6. Results conclude that there was no degradation product and the drug was stable at $4^{\circ} \mathrm{C}$ for at least 15 days. It is indicated that there is a possibility of using the samples over a period of 15 days at refrigerator without degradation.

Table 6 Determination of tiemonium methylsulphate in pharmaceutical formulation by the proposed method

\begin{tabular}{|c|c|c|c|c|c|}
\hline \multirow{2}{*}{ Drug name } & \multicolumn{2}{|c|}{ Conc. $\mu g \mathrm{~mL}^{-1}$} & \multirow{2}{*}{ RSD(\%) } & \multirow{2}{*}{$\% \mathbf{R}$} & \multirow{2}{*}{ Average $\mathbf{R}(\%)$} \\
\hline & Added & Found & & & \\
\hline \multicolumn{6}{|l|}{ Tablet } \\
\hline \multirow[t]{2}{*}{ Algin } & 3 & $2.18 \pm 0.08$ & 2.17 & 72.71 & 72.56 \\
\hline & 5 & $3.62 \pm 0.19$ & 3.21 & 72.41 & \\
\hline \multirow[t]{2}{*}{ Visceralgin } & 3 & $2.34 \pm 0.03$ & 0.73 & 77.99 & 76.06 \\
\hline & 5 & $3.7 I \pm 0.01$ & 0.23 & 74.14 & \\
\hline \multirow[t]{2}{*}{ Visrul } & 3 & $2.28 \pm 0.005$ & 0.12 & 75.96 & 76.06 \\
\hline & 5 & $3.81 \pm 0.04$ & 0.65 & 76.16 & \\
\hline \multirow[t]{2}{*}{ Timozin } & 3 & $2.29 \pm 0.005$ & 0.14 & 76.37 & 73.88 \\
\hline & 5 & $3.56 \pm 0.001$ & 0.02 & 71.39 & \\
\hline \multirow[t]{2}{*}{ Norvis } & 3 & $2.62 \pm 0.03$ & 0.85 & 87.52 & 86.41 \\
\hline & 5 & $4.26 \pm 0.02$ & 0.31 & 85.31 & \\
\hline \multicolumn{6}{|l|}{ (Injection) } \\
\hline \multirow[t]{2}{*}{ Algin } & 3 & $2.14 \pm 0.03$ & 0.29 & 71.41 & 71.13 \\
\hline & 5 & $3.54 \pm 0.06$ & 0.07 & 70.85 & \\
\hline \multirow[t]{2}{*}{ Visceralgin } & 3 & $2.39 \pm 0.04$ & 0.12 & 67.78 & 69.63 \\
\hline & 5 & $3.57 \pm 0,06$ & 0.43 & 71.49 & \\
\hline \multicolumn{6}{|l|}{ (Syrup) } \\
\hline \multirow[t]{2}{*}{ Algin } & 3 & $2.29 \pm 0.03$ & 0.39 & 76.37 & 75.44 \\
\hline & 5 & $3.72 \pm 0.06$ & 0.09 & 74.51 & \\
\hline \multirow[t]{2}{*}{ Visrul } & 3 & $2.17 \pm 0.03$ & 0.98 & 72.38 & 69.25 \\
\hline & 5 & $3.30 \pm 0.05$ & 0.17 & 66.13 & \\
\hline
\end{tabular}

Table 7 Determination of tiemonium methylsulphate in biological sample by the proposed method

\begin{tabular}{|c|c|c|c|c|c|c|}
\hline \multirow{2}{*}{ Biosamples } & \multirow{2}{*}{ Drug(Injection) } & \multicolumn{2}{|c|}{ Conc. $\mu g m L^{-1}$} & \multirow{2}{*}{ Blood conc. } & \multirow{2}{*}{ RSD(\%) } & \multirow{2}{*}{ Recovery(\%) } \\
\hline & & Spiked & Found & & & \\
\hline \multirow{3}{*}{ Blood plasma } & \multirow{6}{*}{ Algin } & 0 & $0.8 I \pm 0.02$ & 0.81 & 1.68 & -- \\
\hline & & I & $1.83 \pm 0.05$ & 0.83 & 1.74 & 102.98 \\
\hline & & 3 & $3.82 \pm 0.04$ & 0.82 & 0.66 & 101.95 \\
\hline \multirow{3}{*}{ Urine } & & 0 & $0.06 \pm 0.003$ & 0.061 & 1.81 & -- \\
\hline & & 1 & $1.06 \pm 0.008$ & 0.061 & 0.45 & 100 \\
\hline & & 3 & $3.06 \pm 0.006$ & 0.06 & 0.11 & 98.4 \\
\hline
\end{tabular}




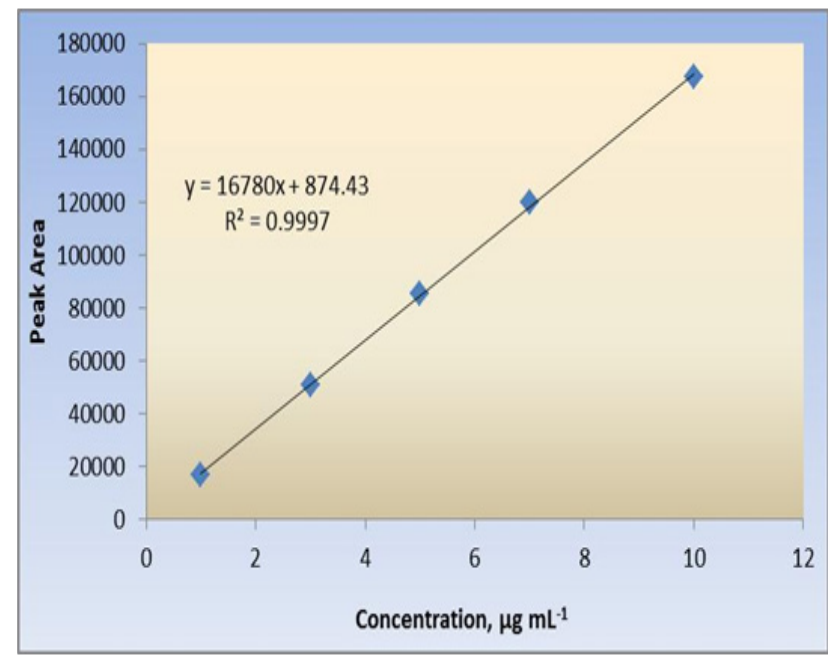

Figure 4 Calibration curve for the determination of tiemonium methyl sulphate.

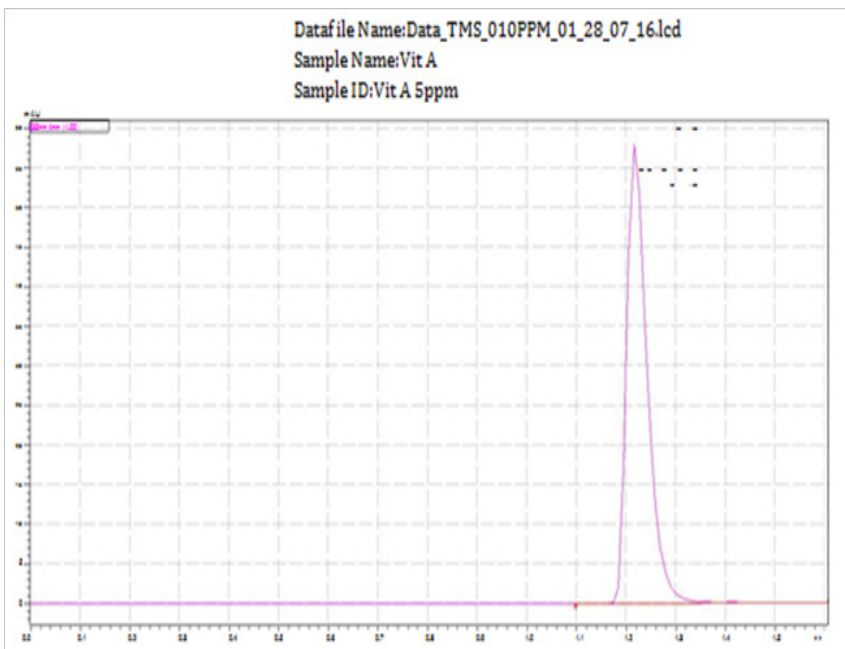

Figure 5 Typical UPLC chromatogram of the examined drug $\left(10 \mu \mathrm{gL}^{-1}\right)$ in pharmaceutical formulation. Chromatographic conditions are described in text. Peaks, I.20min (TMS).

\section{Degradation kinetics}

Rate constant of degradation can be determined by plotting $\log (\mathrm{a}-\mathrm{x})$ after definite time interval, $t$ (days) when a straight line with negative slope is obtained (Figure 6) indicating that degradation followed first order kinetics having the rate constant, $\mathrm{k}$ value of $0.0226 \mathrm{day}^{-1}$. Where, $\mathrm{a}$ is the initial concentration and $\mathrm{x}$ is the degraded concentration after definite time interval.

\section{Column efficiency}

For the assurance of the quality performance of a chromatographic system test of column efficiency is essential. Parameters theoretical plate number, tailing factor and capacity factor have been calculated for a representative chromatogram. The tabulated values as shown in Table 5 revealed the excellent column performance.

\section{Application of the method}

\section{Pharmaceutical formulations}

The method developed here was applied to pharmaceutical products for determining the content of TMS. Figure 4 represents a typical UPLC chromatogram of the examined drug $\left(5 \mu \mathrm{g} \mathrm{mL}^{-1}\right)$ in pharmaceutical formulation. Solutions of various concentrations, 3.0, $5.0 \mu \mathrm{g} \mathrm{mL}^{-1}$ been prepared from different formulation. The overall drug percentage recoveries and the RSD values of the triplicate measurements are calculated and presented in Table 6. TMS content in formulations was determined free of interference from degradation products or the sample excipients while measuring at this detection wavelength indicating. Results indicate the high specificity of the method and measurements are acceptable with good precision. Recovery was almost same as that of levelled values for tested samples. Some contain excessive lower amount than labelled values. It may be due to lack of proper quality management.

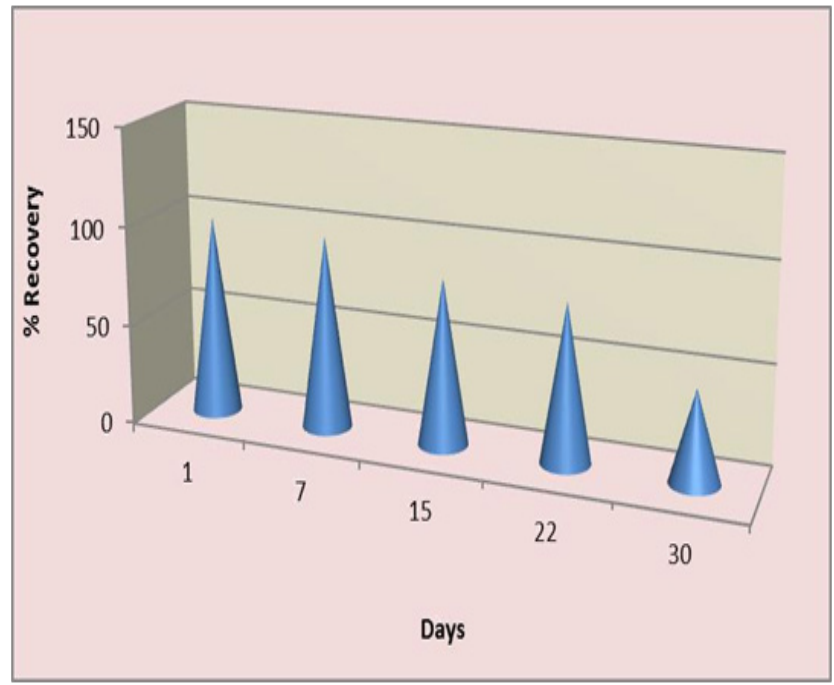

Figure 6 Long term stability graph for Tiemonium methylsulphate.

\section{Application to biosamples}

The absence of any endogenous interfering peak observed (Figure 8 ) in the extracts of bio-fluids overlapping with any analyte indicates the high specificity of the method which can be used in therapeutic and routine analyses. Data of the determination of tiemonium methylsulphate in biological sample by the proposed method has been given in Table 7.

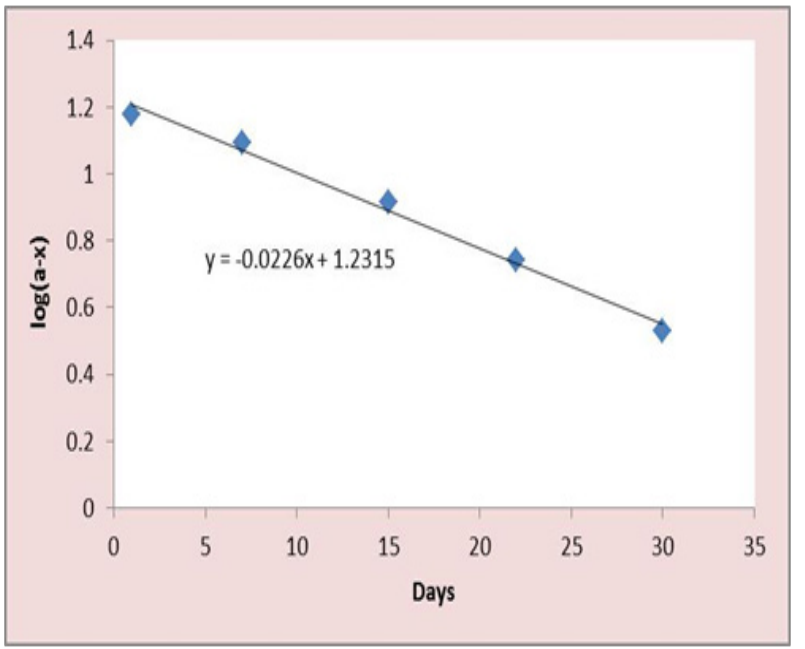

Figure $7 \log (a-x)$ vs time interval, $t$ (days) plot indicating the rate constant of degradation. 


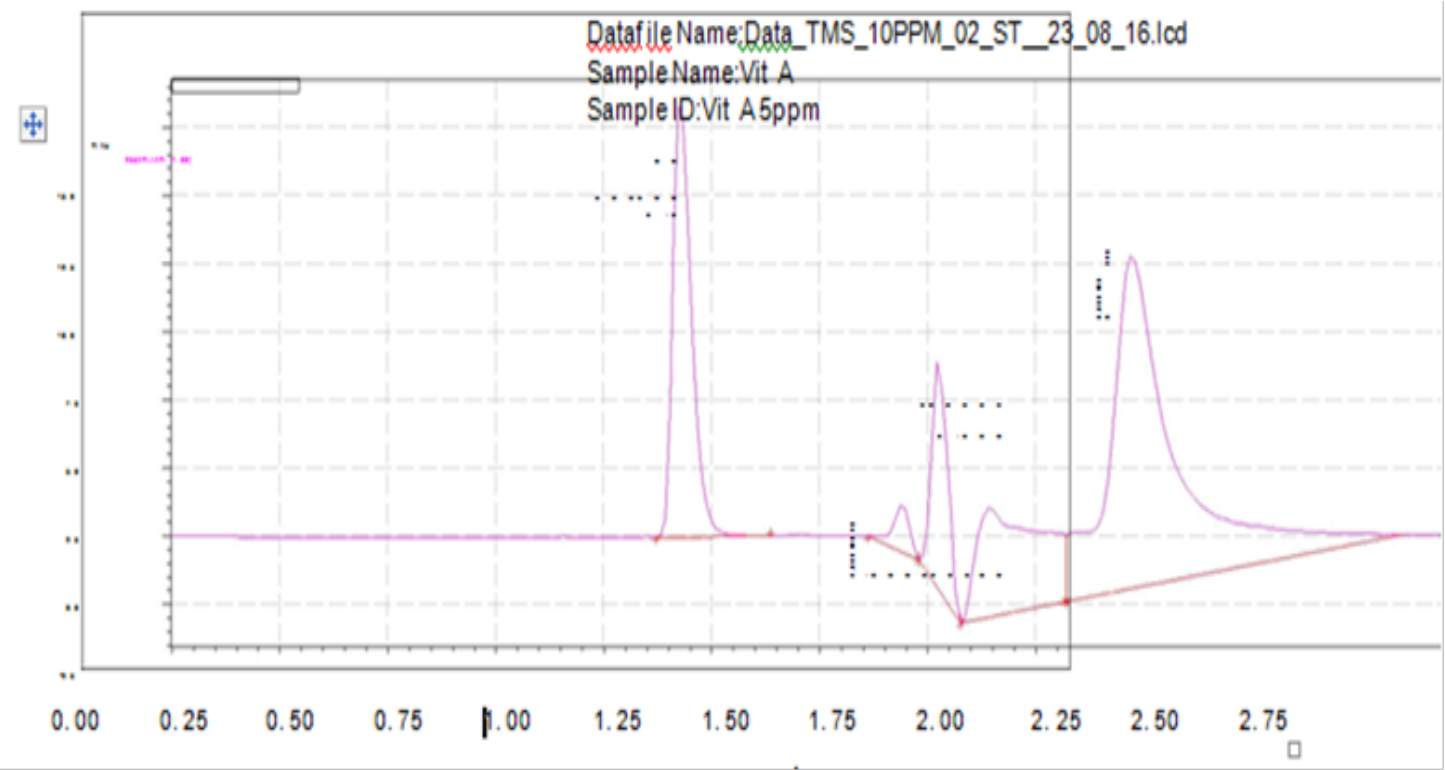

Figure 8 Typical UPLC chromatogram of the TMS $\left(10 \mu g \mathrm{~mL}^{-1}\right)$ in plasma. Chromatographic conditions are described in text. Peaks, $1.177 \mathrm{~min}$ (TMS).

\section{Conclusion}

For the determination of TMS in biofluids the UPLC method presented herein meets the criteria for routine therapeutic drug monitoring or pharmacokinetic studies. The advantage of the method over previously reported methods is the rapidity, simplicity (ease of sample preparation), high sensitivity, and high selectivity. The LOD and LOQ achieved make the assay appropriate for the measurement of therapeutic concentrations. Stability studies showed that the samples can be stored without degradation for a period of up to 7 days. Furthermore the lower solvent consumption along with the significantly reduced run time leads to an environmentally friendly economically analytical procedure that allows for the analysis of a large number of samples over a short period of time.

\section{Acknowledgements}

None.

\section{Conflict of interest}

Author declares that there is no conflict of interest.

\section{References}

1. Bejjani A, Nsouli B, Zahraman K, et al. Swift Quantification of Fenofibrate and Tiemoniummethylsulfate Active Ingredients in Solid Drugs Using Particle Induced X-Ray Emission. Advanced Materials Research. 2011;324:318-323.
2. Islam MS, Wahiduzzaman, Islam MS, et al. UV-Spectroscopic method for estimation of Tiemonium methylsulfate $50 \mathrm{mg}$ tablet in bulk and pharmaceutical preparations. Int J Pharm Sci Res. 2014;5(2):548-55.

3. M Ayad, M El-Balkiny, M Hosny, et al. Spectrophotometric Determination of Tiemonium Methyl Sulfate, Itopride Hydrochloride and Trimebutine Maleate via Ion Pair Complex Formation and Oxidation Reaction. Indian Journal of Advances in Chemical Science. 2016;4(1):85-97.

4. Hala E Zaazaa, Samah S Abbas, Zeina A EL- Sherif, et al. Stability indicating spectrophotometric methods for determination of tiemonium methylsulphate in the presence of its degradation products. J App Pharm Sci. 2014;4(1):33-45.

5. Nesrin K Ramadan, Lamia M Abd El Halim, Hoda F AEL Sanabary, et al. Stability indicating spectrophotometric methods for the determination of Tiemonium Methylsulphate. Int J Drug Dev \& Res. 2014;6(1):160-168.

6. Nesrin K Ramadan, Lamia M Abd El Halim, Hoda FA EL Sanabary, et al. Stability Indicating Chromatographic methods for the Determination of Tiemonium methylsulphate. International Journal of Advanced Research. 2014;2(1):366-376.

7. M Ayad, M El-Balkiny, M Hosny, et al. Green Validated method for determination of tiemonium methyl sulfate using reversed-phase high-performance liquid chromatography technique with stability-indicating studies. Innovare Journal of Medical Science. 2016;4(3):1-9.

8. Validation of Analytical Procedures: Text and Methodology Q2 (R1), Current Step 4 Version, Parent Guidelines on Methodology, ICH Harmonized Tripartite (1996), International Conference on Harmonisation, Geneva, Switzerland; 2005. 